\title{
Is it lawful to offer HIV self-testing to children in South Africa?
}

\author{
A E Strode, ${ }^{1,2}$ LLM; H van Rooyen, ${ }^{3} \mathrm{PhD} ;$ T Makusha, ${ }^{3} \mathrm{PhD}$ \\ ${ }^{1}$ School of Law, University of KwaZulu-Natal, Pietermaritzburg, South Africa \\ ${ }^{2}$ HIV/AIDS Vaccines Ethics Group, School of Applied Human Sciences, University of KwaZulu-Natal, Pietermaritzburg, South Africa \\ ${ }^{3}$ Human Sciences Research Council, South Africa
}

Corresponding author: A E Strode (strodea@ukzn.ac.za)

Health-facility-based HIV counselling and testing does not capture all children and adolescents who are at risk of HIV infection. Self-testing involves conducting an HIV test at home or in any other convenient space without the involvement of a third party. It is increasingly being argued that it should be incorporated into national HIV-prevention programmes as one of a range of HIV counselling and testing approaches. Although this model of HIV testing is being seen as a new way of reaching under-tested populations, no studies have been conducted on offering it to children. HIV self-tests are now available in South Africa and are sold without the purchaser having to be a certain age. Nevertheless, all HIV testing in children must comply with the norms set out in the Children's Act (2005). Here we explore whether offering self-testing to children would be lawful, by outlining the four legal norms that must be met and applying them to self-HIV testing. We conclude that, although children above the age of 12 years could consent to such a test, there would be two potential obstacles. Firstly, it would have to be shown that using the test is in their best interests. This may be difficult given the potential negative consequences that could flow from testing without support and the availability of other testing services. Secondly, there would need to be a way for children to access pre- and posttest counselling or they would have to be advised that they will have expressly to waive this right. The tests are more likely to be lawful for a small sub-set of older children if: $(i)$ it assists them with HIV-prevention strategies; (ii) they will be able to access treatment, care and support, even though they have tested outside of a health facility; and (iii) psychosocial support services are made available to them via the internet or cell phones.

S Afr J HIV Med 2013;14(4):151-154. DOI:10.7196/SAJHIVMED.987

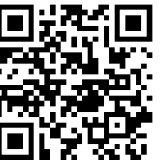

Globally, in 2010, 3.4 million children aged $<15$ years were HIV-positive, $90 \%$ of whom were living in sub-Saharan Africa. ${ }^{[1]}$ In 2011, UNAIDS estimated that in South Africa (SA) alone there were about 460000 children aged 0 - 14 years living with HIV. Health-facility-based HIV counselling and testing (HCT) does not capture all children and adolescents who are at risk of HIV infection. ${ }^{[2-5]}$ The large number of children not treated suggests that there are still relatively low rates of testing among children. ${ }^{[6]}$ Children are either being missed by the prevention of mother-to-child transmission of HIV (PMTCT) services, are surviving past two years of age without being tested, or are infected after birth through child abuse or health-service-acquired infection. In addition, children aged $>12$ years may be at increased risk because of their own sexual activity. ${ }^{[-9]}$ Similarly, rates of testing among adolescents are particularly low, especially among young males, despite this being an at-risk population. ${ }^{[9]}$ This highlights the need for new, targeted, innovative, age-appropriate counselling and testing services for children and adolescents. ${ }^{[10]}$

Low uptake of HIV testing is attributed to both supply and demand factors. On the supply side, key factors include inconvenient clinic hours, the inaccessibility of health facilities and the high cost of travelling to clinics. ${ }^{[11]}$ In terms of demand, even if testing services are available, these do not always translate into willingness to test. ${ }^{[12]}$ Research has shown that deep-seated concerns regarding stigma, discrimination and the fear of positive results act as barriers to increased uptake of HIV-testing services in high HIV prevalence settings. ${ }^{[13]}$

HIV self-testing (HST) refers to the performance of a simple saliva or blood-based test similar to a pregnancy test in the privacy of a home or in any other convenient space without the involvement of a third party. ${ }^{[1,15]}$ Richter et al. ${ }^{[16]}$ point to four potential benefits of such testing; it could: encourage regular HIV testing, allay fears of stigma and possible breaches of confidentiality, decrease the overall costs of HIV testing through removing the need for face-to-face counselling, and facilitate earlier diagnosis and access to treatment. Based on increasing evidence from feasibility and acceptability studies, activists and public health policy-makers have argued that HST should be incorporated into national HIV-prevention programmes as one of a range of community-based HCT approaches ${ }^{[17,18]}$ Community-based HCT models such as home-based and mobile testing have significantly improved testing uptake and have reached higher rates of first-time testers in sub-Saharan Africa. ${ }^{[19-23]}$

HIV self-tests are now available in SA. They sell for approximately R100 at pharmacies and have a shelf-life of two years. They can also be ordered via the internet. ${ }^{[24]}$ Detailed instructions are in the packaging and they generally require the user to place a drop of blood on a test strip; if a dark line develops on the strip, it indicates that the person is HIV- 
positive. ${ }^{[24]}$ Highly accurate oral self-test kits exist with a sensitivity of $92 \%$ and a specificity of $99.9 \%{ }^{[1724]}$ While some HIV self-tests are available in SA, the distribution and use of these tests is largely unregulated as the country's legal and policy frameworks do not specifically allow for their dissemination. ${ }^{[16]}$ This means that there are no specific regulatory restrictions on the sale of such products to persons aged $<18$ years. Nevertheless, all HIV testing in children must comply with the norms set out in the Children's Act (2005), and accordingly, regardless of the model of testing, must meet these minimum standards. ${ }^{[25]}$

Although this innovative model of HIV testing is being seen as a new way of reaching under-tested populations, no studies have been conducted on offering HST to children. There has also not been any conceptual work exploring: (i) whether this is an appropriate model of testing to offer to children; and (ii) if it was found to be acceptable, whether there would be country-specific legal barriers to providing it to them. Here we explore whether offering self-testing to children would be lawful in terms of the Children's Act, by outlining the four legal norms that must be met and by applying them to HST.

\section{The legal framework}

The Children's Act (2005) describes the rights of children to consent independently to a number of health interventions. ${ }^{[26]}$ It provides expressly for when and how HIV testing may be done with children. The drafters of the Act considered HIV testing to be an area in which children's rights were being abused and special protection was needed. Accordingly, sections (s) 130 - 133 of the Children's Act create four norms regulating HIV testing. These are that a child: (i) may only be tested for HIV in specific circumstances (s 130(1)(a) - (b); (ii) must be counselled before and after the HIV test (s 130(1)(a) and 132); (iii) can consent independently to an HIV test from the age of 12 years (s 130(2)); and (iv) has a right to privacy regarding their HIV status (s 133).

\section{The circumstances in which a child may be tested for HIV}

Parliament has expressly limited the circumstances in which HIV testing may be undertaken with children. ${ }^{[25]}$ The Act provides that, other than in exceptional circumstances, HIV testing in children will only be lawful if it is in the best interests of the child and is undertaken with consent. ${ }^{[25]}$ This means that, unlike most other health interventions where children of a certain age or with a particular level of capacity can autonomously choose the intervention, with HIV testing it must be demonstrated that taking the test is in their best interests. ${ }^{[26]}$

Our courts have generally held that in determining the best interests of the child, an effort must be made to establish if a decision will promote a child's physical, moral, emotional and spiritual welfare. ${ }^{[27]}$ Furthermore, it should be seen as a flexible standard which is applied with due consideration to the individual circumstances of the child. ${ }^{[28]}$ The Children's Act gives substance to this assessment by listing a number of factors that should be used in such an analysis. These include: the effect that the decision will have on the child's circumstances, its impact on their physical and emotional security, as well as the need to protect the child from physical or psychological harm. ${ }^{[25]}$

If we apply these principles to HIV testing generally, we would argue that testing undertaken for prevention or treatment purposes would be in the best interests of the child as it promotes their right to basic healthcare services in terms of s 28 of the Constitution. ${ }^{[29]}$ However, HIV testing aimed at discovering a child's HIV status and using this information to discriminate against the child, by e.g. withholding a bursary for tertiary education, would be contrary to the child's best interests.

If we apply these principles to HST specifically, we submit that the following factors would need to be taken into account in establishing whether it could be in the child's best interests: (i) the emotional impact of a child discovering their HIV status on their own, and potentially without support; (ii) the possibility that adults could use self-testing to coerce children to be tested for HIV; (iii) the confidential nature of such testing, which may meet the needs of some adolescents with privacy concerns; (iv) the availability and accessibility of other forms of HIV testing; $(v)$ the child's age, level of maturity and ability to cope with this particular form of testing; ( $v i$ ) the views of the individual child on HST; and (vii) the capacity of the child to consent to the HIV test.

If we weigh and balance the above factors, we would argue that HST could not be considered to be in the 'best interests' of all children. Our reasons are: Firstly, several authors have suggested that many would be too young to cope with the impact of receiving an HIV test result on their own. Secondly, others have suggested that in the absence of pre- and post-counselling there is potentially a risk of suicide for an individual who might be distressed. ${ }^{[30]}$ Thirdly, a study conducted in Kenya $^{[3]]}$ revealed that the main challenge of a self-testing programme was providing links to support services. Napierala Mavedzenge et al. ${ }^{[32]}$ highlight how HST delinks testing and counselling, potentially depriving individuals of access to a range of critical services. ${ }^{[32]}$ Furthermore, if other testing services are accessible and available, it would seem more appropriate that young children use such services where they can be assured of both support and access to treatment. Fourthly, there are some concerns in the literature that self-testing may not be in the best interests of children in that it could be used in a coercive way in the home environment and could possibly result in an abuse of individual rights. It appears that the authors are alluding to the possibility of the test being used by adults to test children at home as, e.g., 'punishment' for being sexually active. Given that the test is done in private, it would always be difficult to ensure that it is not being undertaken for the benefit of third parties. However, there are no data available to support this potential risk. ${ }^{[32,33]}$

Nevertheless, it is possible that for certain older children (aged $\geq 16$ years) who are at high risk of HIV infection, this may be a testing model that appeals. We base this on the emerging evidence on self-testing for adults. Several studies have documented high acceptability, uptake and accuracy of oral self-testing. ${ }^{[20,34]}$ Furthermore, adult users of HIV selftests have found them easy to use, the instructions comprehendible, ${ }^{[35]}$ and that they have a high level of accuracy (99.2\%). ${ }^{[20]}$ This model of testing offers high levels of personal control to children with the capacity to consent to testing and privacy for those who wish to establish their HIV status without the involvement of a third party. If accompanied by alternative forms of support such as telephone counselling or internetbased advice, children may not necessarily be lost to care.

\section{Consent}

The Children's Act states that children aged $>12$ years can consent independently to an HIV test. ${ }^{[26]}$ Given that there is no express capacity requirement for HIV testing, it is presumed that all children aged $>12$ years can make this decision. ${ }^{[27]}$

If we apply these principles to HST, it means that children as young as 12 years could theoretically consent without assistance to an HIV selftest, provided that the other obligations in the Children's Act relating to 
the best interests of the child and counselling are met. One issue raised in the literature is the possibility of such consent being coerced. ${ }^{[33]}$ Accordingly, it has been submitted that to avoid this possibility, laws and policies should be put in place to ensure that vulnerable groups such as children are not tested against their will. ${ }^{[36]}$

\section{Pre- and post-test counselling}

The Children's Act (s 132) requires pre- and post-test counselling by an appropriately trained person. The Act does not describe the manner in which the counselling should be provided or the information that must be given to children during the counselling processes. McQuoidMason $^{[37]}$ submits that this provision simply means that 'during pre-test counselling the benefits, risks and social implications of an HIV test must be explained to the child, while during post-test counselling the implications of the results must be explained'.

The lack of accompanying counselling is a key concern in the literature on self-testing. ${ }^{[36]}$ It has been argued that pre-test counselling provides an opportunity to make informed decisions on whether to test or not, while post-test counselling informs individuals of their HIV status, provides information on HIV prevention, encourages them to test regularly, reduces the risk of HIV transmission to others, and offers psychosocial or referral support to HIV-positive clients. ${ }^{[36]}$

Counselling is a mandatory requirement in the Children's Act, which means that testing without counselling is unlawful unless a child waives their right to this service. This therefore serves as an obstacle to self-testing by SA children. The Act does not specify the nature of the counselling; thus, it is possible that, e.g., telephone counselling could suffice. The National HIV Counselling and Testing Policy also does not specify that counselling must be face to face. Instead, it provides a list of the minimum information that should be provided in pre-and post-test counselling sessions. ${ }^{[38]}$

\section{Confidentiality}

The Children's Act (s 133) provides that children have the right to confidentiality regarding their HIV status. ${ }^{[2]}$ Furthermore, information on a child's HIV-positive status may only be disclosed with the consent of that child if they are aged $>12$ years. ${ }^{[37]}$

A key strength of the self-testing approach is that it ensures that confidentiality is maintained. A study conducted in Singapore ${ }^{[39]}$ found that confidentiality was a key reason why people preferred to buy overthe-counter HIV test kits. The right to confidentiality in the Children's Act is therefore not a barrier to self-testing.

\section{Conclusion}

There is some preliminary evidence that HST could be a valuable new HIV-prevention strategy in that it gives persons at risk of HIV infection another way of discovering their HIV status. Although no research has been undertaken on whether this model is suitable for children, we argue that this work needs to be done as a matter of urgency, as they are a group at high risk of HIV infection.

This review of the SA legal framework has shown that the law does not expressly prohibit or regulate the offering of self-tests to children. Nevertheless, the way in which self-testing was offered would have to comply with the Children's Act. This means that only children aged $>12$ years could use an HIV self-test on their own, as below this age they do not have the capacity to consent. Furthermore, there would be two potential legal obstacles. Firstly, it would have to be shown that using an HIV self-test is in their best interests. This standard may be hard to meet, given the potential negative consequences that could flow from testing without support and the availability of other forms of HIV testing. Secondly, there would need to be a way for children to access pre- and post-test counselling or for children to be advised that they will expressly have to waive this right. Thus, simply offering self-HIV tests to all children aged $>12$ years would not be lawful, unless it could be shown that it was in their best interests and that counselling was provided.

Given these legal obstacles, we would suggest that it is only a small sub-set of children for whom such testing would be considered lawful. We argue that for older children (aged $>16$ years) self-testing may be in their best interests if: (i) it assists them with HIV-prevention strategies; (ii) they will be able to access treatment, care and support even though they have tested outside of a health facility; and (iii) psychosocial support services are made available to them via the internet or cell phones.

It is submitted that although self-testing in children is an underexplored issue, it requires further debate and discussion. Policy guidance is needed on when a self-test would be in a child's best interests and how children who choose such a testing model can receive counselling and appropriate referral to services, if required.

Acknowledgements. This article was made possible by funding from the National Institutes of Health (NIH) awarded to the HIV AIDS Vaccines Ethics Group (HAVEG) via the Desmond Tutu HIV Foundation (DTHF) (1RO1 A1094586) CHAMPS (Choices for Adolescent Methods of Prevention in South Africa). The opinions expressed herein are the views of the authors. They do not represent any position or policy of the NIH.

\section{References}

1. WHO, UNICEF, UNAIDS. Global HIV/AIDS response. Epidemic update and health sector progress towards universal access. Progress report. Geneva, Switzerland: WHO UNICEF, UNAIDS, 2011.

2. Bwambale F, Ssali S, Byaruhanga S, Kalyango J, Karamagi C. Voluntary HIV counselling and testing among men in rural western Uganda: Implications for HIV prevention. BMC Public Health 2008;8(1):263. [http://dx.doi.org/10.1186/14712458-8-263]

3. Hutchinson PL, Mahlalela X. Utilization of voluntary counseling and testing services in the Eastern Cape, South Africa. AIDS Care 2006;18(5):446-455.

4. Chhagan MK, Kauchali S, Arpadi SM, et al. Failure to test children of HIV-infected mothers in South Africa: Implications for HIV testing strategies for preschool children. Trop Med Int Health 2011;16(12):1490-1494. [http://dx.doi.org/10.1111/ j.1365-3156.2011.02872.x]

5. Venkatesh KK, Madiba P, de Bruyn G, Lurie MN, Coates TJ, Gray GE. Who gets tested for HIV in a South African urban township? Implications for test and treat and gender-based prevention interventions. J Acquir Immune Defic Syndr 2011;56(2):151-165. [http://dx.doi.org/10.1097/QAI.0b013e318202c82c]

6. Shisana O, Rehle T, Simbayi LC, et al. South African National HIV Prevalence, Incidence, Behaviour and Communication Survey, 2008: A Turning Tide Among Teenagers? Cape Town: HSRC Press, 2009.

7. Lesch A, Swartz L, Kagee A, et al. Paediatric HIV/AIDS disclosure: Towards a developmental and process-oriented approach. AIDS Care 2007;19(6):811-816.

8. Rotheram-Borus MJ, Flannery D, Rice E, Lester P. Families living with HIV. AIDS Care 2005;17(8):978-987.

9. Ramirez-Avila L, Nixon K, Noubary F, et al. Routine HIV testing in adolescents and young adults presenting to an outpatient clinic in Durban, South Africa. PLoS One 2012;7(9):e45507. [http://dx.doi.org/10.1371/journal.pone.0045507]

10. Kellerman S, Essajee S. HIV Testing for children in resource-limited settings: What are we waiting for? PLoS Med 2010;7(7):e1000285. [http://dx.doi.org/ 10.1371 journal.pmed.1000285]

11. Negin J, Wariero J, Mutuo P, Jan S, Pronyk P. Feasibility, acceptability and cost of home-based HIV testing in rural Kenya. Trop Med Int Health 2009;14(8):849-855.

12. Cremin I, Cauchemez S, Garnett GP, Gregson S. Patterns of uptake of HIV testing in sub-Saharan Africa in the pre-treatment era. Trop Med Int Health 2012;17(8):e26-e37.

13. Kalichman SC, Simbayi LC. HIV testing attitudes, AIDS stigma, and voluntary HIV counselling and testing in a black township in Cape Town, South Africa. Sex Trans Infect 2003;79(6):442-447.

14. Frerichs R. Personal screening for HIV in developing countries. Lancet 1994;343(8903):960-962. 
15. Merson MH, Feldman EA, Bayer R, Stryker J. Rapid self testing for HIV infection. Lancet 1997;349(9048):352-353.

16. Richter M, Venter WDF, Gray A. Home self-testing for HIV: AIDS exceptionalism gone wrong. S Afr Med J 2010;100:636-642.

17. Myers JE, El-Sadr WM, Zerbe A, Branson BM. Rapid HIV self-testing: Long in coming but opportunities beckon. AIDS 2013;27(11):1687-1695. [http://dx.doi org/10.1097/QAD.0b013e32835fd7a0]

18. Krause J, Subklew-Sehume F, Kenyon C, Colebunders R. Acceptability of HIV self-testing: A systematic literature review. BMC Pub Health 2013;13:735. [http:// dx.doi.org/10.1186/1471-2458-13-735]

19. van Dyk AC. Client-initiated, provider-initiated, or self-testing for HIV: What do South Africans prefer? J Assoc Nurses AIDS Care 2013 (in press).

20. Choko A, Desmond N, Webb E, et al. The uptake and accuracy of oral kits for HIV self-testing in high HIV prevalence setting: A cross-sectional feasibility study in Blantyre, Malawi. PLoS Med 2011;8(10):e1001102. [http://dx.doi.org/10.1371/ journal.pmed]

21. Frith L. HIV self-testing: A time to revise current policy. Lancet 2007;369(9557):243245.

22. Ganguli I, Bassett I, Dong K, Walensky R. Home testing for HIV infection in resource-limited settings. Curr HIV/AIDS Rep 2009;6(4):217-223.

23. Wright AA, Katz IT. Home testing for HIV. N Engl J Med 2006;354(5):437-440.

24. eGenie. HIV home test kits. http://testforhiv.egenie.co.za/index.php?hur=87 (accessed 8 November 2013).

25. Government of South Africa. Children's Act: No. 38 of 2005. Pretoria: Government of South Africa, 2005.

26. Strode A, Slack C, Essack Z. Child consent in South African law: Implications for researchers, service providers and policy-makers. S Afr Med J 2010;100(4):247-249. 27. McCall v McCall, 1994 (3) SA 201 (C).

28. S v M (Centre for Child law as Amicus Curiae, 2008).

29. Grant K, Lazarus R, Strode A, van Rooyen H, Vujovic M. Legal, Ethical and
Counselling Issues Related to HIV Testing of Children HIV testing of Children Legal Guidelines for Implementers. Pretoria: Human Sciences Research Council, 2012.

30. World Health Organization. Report on the First International Symposium on Self-testing for HIV: The Legal, Ethical, Gender, Human Rights and Public Health Implications of HIV Self-testing Scale-up. Geneva: WHO, 2013.

31. Kalibala S, Tun W, Muraah W, Cherutich P, Oweya E, Oluoch P. "Knowing Myself First": Feasibility of Self-testing Among Health Workers in Kenya. Nairobi: Population Council, 2011.

32. Napierala Mavedzenge S, Baggaley R, Corbett EL. A review of self-testing for HIV: Research and policy priorities in a new era of HIV prevention. Clin Infect Dis 2013;57(1):126-138. [http://dx.doi.org/10.1093/cid/cit156]

33. Richter ML, Venter WD, Gray A. Forum: Enabling HIV self-testing in South Africa. Southern African Journal of HIV Medicine 2012;13(4):186-187. [http:// dx.doi.org/10.7196/SAJHIVMED.858]

34. Gaydos CA, Hsieh Y-H, Harvey L, et al. Will patients "Opt In" to perform their own rapid HIV test in the emergency department? Ann Emerg Med 2011;58(Suppl 1):S74-S78. [http://dx.doi.org/10.1016/j.annemergmed.2011.03.029]

35. Lee VJ, Tan SC, Earnest A, Seong PS, Tan HH, Leo YS. User acceptability and feasibility of self-testing with HIV rapid tests. J Acquir Immune Defic Syndr 2007;45(4):449-453.

36. Gardner J. HIV home testing - a problem or part of the solution? South African Journal of Bioethics and Law 2012;5(1):15-19.

37. McQuoid-Mason DJ. The effect of the new Children's Act on consent to HIV testing and access to contraceptives by children. S Afr Med J 2007;97(12):1252.

38. National Department of Health. National HIV Counselling and Testing (HCT) Policy Guidelines. Pretoria: NDoH, 2010.

39. Ng OT, Chow ALL VJ, Chen MI, et al. Accuracy and user-acceptability of HIV self-testing using an oral fluid-based HIV rapid test. PLoS One 2012;7(9) [http://dx.doi.org/10.1371/journal.pone.0045168] 